\title{
Health support needs of widows in South Africa: A phenomenological inquiry
}

\section{Gopolang L Sekgobela}

Department of Nursing Science, Faculty of Health Sciences, University of Pretoria, Private Bag X323, Arcadia, 0007, Pretoria, South Africa

\section{Dorricah Peu}

Department of Nursing Science, Faculty of Health Sciences, University of Pretoria, Private Bag X323, Arcadia, 0007, Pretoria, South Africa

\section{Anna E van der Wath*}

Faculty of Health Sciences, Department of Nursing Science, University of Pretoria, Private Bag X323, Arcadia, 0007, Pretoria, South Africa

*Corresponding Author: Anna van der Wath, Department of Nursing Science, University of Pretoria, Pretoria, South Africa

Email: annatjie.vanderwath@up.ac.za

Phone: 2712845063142

\begin{abstract}
Community healthcare should facilitate effective adaptation to widowhood. In South Africa, the primary health care nurses, who are the first line health care services, seem to miss opportunities for identifying and effectively managing widows experiencing health risks. This study explored the health-support needs of widows. We purposively selected 12 participants, who were widows between 25 and 65 years old residing in an urban area of South Africa. Data were gathered during unstructured individual phenomenological interviews and analysed using a descriptive phenomenological method. Widowhood is an embodied and intense emotional experience with a cognitive impact. Related to these experiences are widows' health-support needs. Widows have a need to be listened to, to be
\end{abstract}


understood and cared for; attitudes and skills which require time and availability from primary healthcare nurses. Widows expressed a need to engage in support groups, receive home visits and health education from primary healthcare nurses.

\section{Keywords}

Bereavement, health support needs, widowhood, loss, grief

\section{Introduction}

Widowhood "does more than just make people sad; it changes their lives in fundamental ways" (Lee, 2014, p. 3). Both widowed women and men experience lower levels of physical and psychological wellbeing (Bennett \& Soulsby, 2012; Stroebe, Schut, \& Stroebe, 2007; Vasunilashorn \& Choi, 2014). Women seem to be more vulnerable to the physical health challenges associated with widowhood (Das, 2013), while the psychological effects are further exacerbated among women related to particular social and cultural aspects (Trivedi, Sareen, \& Dhyani, 2009). Widows are vulnerable to social stigmatization, economic vulnerability, and humanitarian injustices, especially in developing countries (Loomba foundation, 2015). This research was conducted in a developing country, thus the focus on widows as a vulnerable group.

Men and women show different health responses to widowhood. This indicates a need to examine the effects of widowhood for men and women separately (Burns, Browning, \& Kendig, 2015). Widowhood in women is associated with a high rate of chronic conditions and health events, for example, cardiovascular events, chronic pain (DiGiacomo, Davidson, Byles, \& Nolan, 2013), hypertension (Perkins et al., 2016) and weight and blood glucose control problems (Das, 2013). On a psychological level, the death of a spouse is a stressful life event which represents a turning point in a woman's life (Ali \& Shanif, 2016; Utz, 
Caserta, \& Lund, 2011). Widows experienced greater anxiety and lesser happiness in comparison to males (Chatterjee, 2016). For both men and women, becoming widowed clearly relates to a strong decline in positive affect, while only women reported an increased number of depressive symptoms (Burns et al., 2015).

Although grief can be very stressful and disruptive, most bereaved survivors gradually cope with the support of others and manage to restore meaning in their lives (Shear, 2012). About 7\% of bereaved people develop complicated grief (Simon, 2013), a condition where the person's adaption to and acceptance of the reality of the loss is complicated, delayed, distorted or prolonged. People who develop complicated grief may experience reduced quality of life and other physical and psychological symptoms leading to adverse health outcomes (Lobb et al., 2012; Simon, 2013).

The various health concerns experienced by widows signal their increased need for support and use of health care services. Healthcare providers should be aware that the impact of widowhood is an individualised experience with a risk of adverse health outcomes. Widows at risk of adverse health outcomes should be identified to meet their support needs (DiGiacomo et al., 2013; Schut \& Stroebe, 2010; Wickert, 2010). Community health workers are ideally situated to provide support that will facilitate effective adaptation to widowhood (Ali \& Shanif, 2016) and should be equipped to recognize and refer widows with complicated grief for management (Shear, 2012).

In the first author's experience as a psychiatric nurse in South Africa, primary health care nurses who are the first line health care services, seem to miss opportunities to identify and effectively manage widows experiencing health risks. During personal contact with widows at forums, at social and religious events, the first author realised that many widows appeared to be sad, exhibited low morale and complained of health problems. The widows were reluctant to visit their local primary health care clinics since they were not receiving 
appropriate support. Health care providers may overlook behavioural changes caused by widowhood and assume normal reactions to loss. Changes experienced in widowhood may be exacerbated by underlying psychological trauma leading to undue stress in widows. Appropriate grief counselling and support need to be provided in a timely manner to prevent unfavourable health outcomes (Busari \& Folaranmi, 2014).

To provide appropriate support, healthcare workers should be knowledgeable of widows' particular support needs. Research describing widow's support needs from their own perspective is thus important to create awareness and increase responsiveness of healthcare workers (Lowe \& McClement, 2011; DiGiacomo et al., 2013). To this end, we explored the health-support needs of widows in South Africa. The research was guided by the French phenomenologist, Merleau-Ponty's philosophy (1908-1961). Merleau-Ponty explored the grounds of being in the world by emphasising the bodily structure of being. He turned the attention of phenomenology to the body as it is experienced (Dahlberg, Dahlberg, \& Nystrom, 2008; Garner, 1993). "To perceive is to render oneself present to something through the body" (Merleau-Ponty, 1964, p. 138-9). Merleau-Ponty (1945/1962, p. 452) rooted experiences in a person's direct contact with his/her existence, “...by being this body and this situation..." Humans' connectedness with the world and others implicates a relationship between the human and the world; as such the understanding of the lifeworld is a necessary condition for knowledge (Dahlberg et al., 2008). We assumed that, when widows were asked about their health-support needs during the research interviews, they presented their experiences in terms of their embodied presence as widows at the primary healthcare clinic, seeking support for certain health needs The essence of these experiences may enable the primary healthcare nurses to better understand the health-support needs of widows. 


\section{Materials and Methods}

The research followed a descriptive phenomenological approach as proposed by Giorgi (2009) and Dahlberg et al. (2008) (called "lifeworld research"). Descriptive phenomenology lends itself to explore the experiences of bereavement, widowhood and loneliness in-depth, as illustrated in studies by Doherty and Scannell-Desch (2008); McInnis and White (2001); Muller and Thompson (2003); and Rodger, Sherwood, O'Connor, and Leslie (2007).

The study population included widows who were between 25 and 65 years old residing in an urban area of South Africa. The study was introduced to potential participants attending a widows' forum. Potential participants had lost a spouse a year or more before but less than five years before, irrespective of the cause of death. The researcher purposively selected participants who used primary healthcare services. In lifeworld research there is no talk about saturation since lifeworld research holds the ontological and epistemological idea that meanings are infinite, always expanding and extending themselves (Dahlberg et al., 2008). The researcher initially interviewed ten participants. Additional sampling of two more widows provided no new information, only redundancy of previously collected data (Giorgi, 2009). The sample size of 12 widows was adequate to obtain an in-depth understanding of the meaning structure of the widow's self-perceived health care needs.

Interviews were conducted in comfortable and familiar settings for the participants, either at their homes or places of work. Confidentiality and privacy were ensured.

The first author conducted unstructured individual phenomenological interviews. The interviews were audio-recorded and took about 30-55 minutes. Communication techniques such as paraphrasing, clarification, probing and reflecting were used as needed to facilitate the interview. Furthermore, observational notes of verbal and nonverbal cues such as facial expressions and other gestures displayed by the participants, were recorded (Burns \& Grove, 2011). 
During the first step of data analysis, the emphasis was on assuming the phenomenological attitude; this entailed being open and sensitive towards the widows' descriptions of their lifeworld and its meaning (Dahlberg et al., 2008; Giorgio, 2009). We set aside our own values and allowed the multiple realities of the widows' experiences of healthsupport needs to emerge. The second step entailed reading the transcribed interviews to grasp the experiences of the participants from their consciousness and perspectives. During the third step, we segmented descriptions to establish and demarcate "meaning units". Lastly we reflected on the meaning units to accurately understand any revelations pertinent to the phenomenon. The insights obtained were used to transform and summarize the meaning units to reflect the essence of the participants' experiences.

To ensure the rigour of the study, we used phenomenological reduction (bracketing) and reflexivity. The interviewer kept a reflective journal to create conscious self-awareness of her feelings during the interviews and her role in the research process. We attempted to bracket our perceptions of the study phenomenon from those of the participants and tried to avoid our own assumptions shaping our analysis and description of the findings (Hamill \& Sinclair, 2010).

We obtained permission from the Research Ethics Committee of the Faculty of Health Sciences, University of Pretoria to conduct the study. Prior to the interviews, informed consent was signed and participants were made aware that they would be reminded about the death of their spouses and might relive the traumatic experiences. Participants were ensured that their rights to withdraw from the study at any given time would be respected and that they would be referred to a health care practitioner of their choice when needed. Following the interviews, all participants verbalised that they were in a comfortable emotional state and further counselling was not necessary. Each participant was assigned a code number and the 
research report was written in such a way that participants' identities could not be linked to their responses.

\section{Results}

The participants were from Sepedi, Sotho and Tswana ethnic groups. All, except one participant, were employed.

The findings indicated that widowhood is an embodied and intense emotional experience with a cognitive impact. These experiences are related to widows healthsupport needs. Widows need to be treated in a person-centred way which means that their difficulties need to be acknowledged and treated individually. They need to be listened to, to be understood and cared for; attitudes and skills which require time and availability from primary healthcare nurses. Widows expressed a need to engage in support groups, receive home visits and receive health education from primary healthcare nurses.

The participant's number is indicated in brackets following each quotation, for example, P1.

\section{Widowhood is an embodied experience}

Participants revealed their physical experience of widowhood. They experienced physical problems such as lack of energy, lack of appetite, insomnia and pain as illustrated in the following excerpts:

...I did not have energy...I just stayed there [at home]. (P6)

....I also suffered from lack of appetite...I didn't eat well at all...I couldn't finish two slices of bread, it was just too much and because of that I lost a lot of weight... (P10) 
I felt chest pains but never had energy to go to the clinic. I forced myself to go to the clinic because the pain was killing me....I needed these pains to go away and I needed my sleep! (P1)

The following quotation illustrates the embodied emotional experiences of the participant; she felt physically sick, but at the same time experienced deep emotional pain:

I just couldn’t take it...it was too much for me. I got sick...I felt sick...it was as if a part of me died with him and I couldn't bear feeling that hurt...it was just hurtful. (P12)

The effect of the embodied experiences of widowhood was evident when one participant verbalised how she used to wake up in the middle of the night following the death of her husband:

I had some physical problems...one of them was that I would wake up at night, and promptly two o’ clock every night and I am not an insomniac...you know naturally...I sleep until the next morning until my alarm goes off, but during those days...I think maybe almost a year after my husband's passing I found myself waking up in the middle of the night and when I look at my watch its almost the same time, two o'clock in the morning...I don't sleep well at night because I am thinking a lot... (P10)

\section{Widowhood is an intense emotional experience}

All participants experienced feelings of sadness, loss and loneliness. The emotional pain and longing seemed to last forever:

I knew that losing a husband was painful but I never thought it was this miserable. Each day seems to be more miserable than the other and I missed my husband each day... (P6)

The emotions sometimes overcame them in a sudden, intense way:

I cried...I cried...I cried...if I think about it I cry.... (P9) 
The participants embraced and valued the time that they had spent with their lost spouses and, in the process, perceived that life had no meaning without their husbands. The feeling of loss and loneliness is evident in this quotation:

I felt so empty...my life was meaningless (taking a deep breath)...more than twenty-five years of our marriage was lost...I felt lost...I wondered how my life would be from that day...the day I lost him? All these years...he was the first person I saw when I opened my eyes in the morning and the last one I saw in the evening....I missed him so much...life had no meaning without him.... (P11)

Participants expressed feelings of anger, hurt and betrayal towards the world, towards God and towards their husbands for having left them. One participant commented as follows:

I had mixed emotions but the biggest emotion that I had was that of anger...I was angry at...my husband for having gone...I was angry at God for having taken him....I was angry at the world...I was angry at....literally everybody, especially couples....I also looked at the family and accused them sometimes of not being supportive enough... (P10.

\section{Widowhood has a cognitive impact}

Most of the participants experienced a lack of concentration, forgetfulness and recurrent memories. The forgetfulness was illuminated as follows:

I was forgetting important things like fetching my kids from school. (P3)

The disruptive effect of the lack of concentration was evident when one participant described how she used to lose concentration while driving:

I would be driving....and the robots [traffic lights] are red...and the robot further than the one that stopped me opens and I will just move. I don't care if that one is red...but God was so merciful...I 
never had an accident but I think I was not concentrating...lack of concentration and you know forgetfulness... (P10)

Some of the participants expressed difficulty to forget about their circumstances as they described that they had recurrent and intrusive memories of their widowhood experiences as illustrated in this quotation:

...the memory of that day haunts me...I still cannot take it out of my mind. It still keep playing it in my mind...it cannot get away. When I am sitting quietly it just comes back. It can't leave me and it bothers me a lot. (P8)

Some participants verbalised that they had suicidal thoughts as life had no meaning, and one participant expressed that she even attempted to end her life and her child's life:

I also want to die...there is no meaning for me to live anymore...I even tried to kill myself and my child...During the time when I was frustrated and I started thinking about suicide; I became a burden to myself and I did not know how to handle it... (P5)

\section{Health-support needs of widows}

The health-support needs of widows seemed to resemble a need for person-centred care. Participants felt the difficulties widows experience should be acknowledged:

I think something should be done...I don't know what? ...but something should be done to sort of highlight the plight of a widow and to sort of highlight the fact that widowhood has some impact on your health maybe... (P10)

Participants needed to be treated as individuals, according to what they needed as widows, as explained in the following two quotations: 
I would like the services to be considerate of the widows...the system should have emergency support or special support for widows...as needed. (P1)

... and you know sort of attend to the widows as individuals...I know it will be like asking a lot but widows really need attention. (P10)

Participants expressed a need to be listened to, to be understood and cared for, as exemplified in the next excerpt:

I needed someone to listen to me.....to understand what I was going through as a widow. I needed a nurse to become more caring.....taking time to listen to me...not to rush our talk because the queue at the clinic is too long.... (P6)

The same participant indicated that listening requires time and availability:

The sisters should take their time during consultation with widows because I realized that as a widow I cannot just pull up my socks and move on with my life...at least be good listeners. (P6)

\section{Participants expressed a need for support groups:}

...in the clinics they do have some form of support groups because when the nurses talk to patients they would group them...I think maybe once in a while they can just say: "Who are widows here amongst you?" (P10)

...they [the nurses] can maybe have an awareness support groups for widows....if maybe they can form that group because really for me it was...it was very helpful... (P9)

A home visit by nurses was recommended as another need:

I would have liked the nurses to do home visits to clients including widows. The death of my husband was painful for me....I did not feel like going out...I just wanted to stay in bed...I sometimes wished I could talk to someone...a professional....someone who can tell me things will 
be ok.... but I did not have the energy to go to the clinic. Home visits by a nurse could have helped me a lot. (P7)

Participants expressed a need to receive healthcare information, not only on health related issues, but also regarding the grieving process. A lack of information led to frustration as illustrated in this quotation:

I feel that widows should be given information regarding the steps that they will experience following the death of their husband... what needs to be done. I was quite frustrated after my husband's death...I did not know where to go...where to start...because I did not have information and it was frustrating...I think the clinics could assist us....they are near us because they are available in the community...so we can always go to the clinic to get information. At least they should have information regarding all this... (P11)

\section{Discussion}

From a phenomenological perspective, humans are conscious of the world through the medium of their bodies. It is through the body and the bodily experience that the lifeworld becomes meaningful (Merleau-Ponty, 1962). When disturbed, the body senses the problem and becomes an obstacle towards engagement with the world (Dahlberg et al., 2008). Grief is an embodied experience (Lovey, 2016) that re-shapes human experience and renegotiates the relationship between the self and the world (Lucci, 2011). Widowhood is integrated in a woman's subjective body; the body senses and responds to the disruption and the changes that are taking place in the lifeworld. Widowhood can represent what is described by Van Wolputte (2004, p. 263) as "those moments during which the body and bodiliness are questioned and lose their self-evidence", a vulnerability that threatens bodily certainty. Embodied uncertainties challenge the autonomy of the individual on an existential level. It is 
though sometimes through overcoming these disruptions that a sense of belonging is achieved (Van Wolputte, 2004).

Embodied grief has a physical and emotional component; the pain of grief establishes a new relationship between the self and the body (Lucci, 2011). In this study, the participants experienced physical health problems such as lack of energy, lack of appetite, weight loss, disturbed sleeping patterns and pain following widowhood. The physical pain experienced during bereavement may reflect the strength of the connection the person had with the deceased. These "connections are physically and emotionally embedded to constitute a deeply relational [...] embodied self." Loss of connection with a partner is felt and experienced as trauma to the physical body (Ribbens McCarthy, 2012, p. 12).

During bereavement, people may experience worsening health problems and are often diagnosed with new conditions (DiGiacomo et al., 2013; Utz et al., 2011). For example, widowhood is associated with the presence and severity of coronary artery disease (Daoulah et al., 2017) and a range of major cardiovascular events (Carey et al., 2014). The loss of a spouse increases the risk of outpatient psychiatric visits, psychotropic medication and allcause mortality (Möller, Björkenstam, Ljung, \& Åberg Yngwe, 2011). Widowhood substantially increases the mortality levels among broad segments of the population, even after many years (Carr \& Bodnar-Deren, 2009; Roelfs et al., 2012).

Participants in this study felt sad and lonely. They experienced long-lasting emotional pain and longing. Anxiety, yearning, anger and depression were emotional experiences reported by bereaved spouses in a study by Asai et al. (2010). Grief is characterised by an intense yearning or longing for the deceased and strong wishes to be reunited with the lost person (Shear 2012). The yearning and loneliness are described as painful uncontrollable emotions (Ryckebosch-Dayez, Zech, Mac Cord, \& Taverne, 2016). 
The negative emotional experiences become the main source of anxiety and widows struggle to experience happiness again (Chatterjee, 2016), and are more likely to have higher levels of depression during the period following the loss (Kim \& Kim, 2016). The emotional experiences often entail a meaning disruption component which is related to the shock of the loss and the disruption of attachment (Coleman \& Neimeyer, 2010). Widows' intense emotions may partially subside with time, but a range of other outcomes may persist for years after the loss (Das, 2013).

The person's ability to flexibly enhance and suppress the expressions of emotions is associated with the development of complicated grief (Gupta \& Bonanno, 2011). Poor health at the time of widowhood also leads to higher risks of complicated grief and major depressive disorder (Utz et al., 2011).

"We are always thinking says Merleau-Ponty. We are a thinking experience. Thinking is more a situation than an act. We cannot stop thinking because we are open to a field of thought...” (Kwant, 1966, p. 238). The present does not cancel its past, nor will its future cancel its present. Memory reopens time lost and invites a person to capture the situation evoked (Merleau-Ponty, 1962). Bereavement is associated with poorer memory performance within certain sub-groups (Rosnick, Small, \& Burton, 2010). On the contrary, as also reported in this study, widows may experience difficulty forgetting about their circumstances and have recurrent and intrusive memories of the deceased. Ryckebosch-Dayez et al. (2016) describe these memories as loss-oriented stressors that may be triggered by external events (for example, reminders of the deceased) or internal experiences (for example, missing the spouse when fulfilling primary needs such as sleeping or eating). Bereaved persons may try to avoid reminders of the loss (Shear, 2012), but coping through distraction or avoidance of grief may be indicators of poor adjustment (Bennett, Gibbons, \& Mackenzie-Smith, 2010). 
During the embodied moment when acknowledging the discomfort, widows may either draw on their own capacity to cope, or seek help from others, such as primary healthcare services. Widows in the study recommended that primary healthcare nurses should be person-centred and acknowledge their plight as widows. Carl Rogers's person-centred theory $(1951,1961)$ describes what constitutes care of a person-centred nature. The theory is based on constructs such as self-concept, the need for positive regard, psychological climate of a therapeutic relationship and conditions of personality change (Rogers, 1961). The way people perceive and value themselves is central to the person-centred approach. Therapeutic change occurs when a person perceives that he/she is therapeutically understood and accepts his/her own reality and the reality in the social environment. In the context of bereavement, primary healthcare nurses need to empathise with widows, respect their own valuing process, and portray unconditional positive regard for widows to facilitate therapeutic change (Rogers, 1961).

In this study, widows expressed the need for support from primary healthcare nurses based on their unique experiences. The need to tailor bereavement interventions according to the individual's unique needs were highlighted by Lund et al. (2010) and DiGiacomo et al. (2013). The primary healthcare nurse has a responsibility to assess the client's needs, acknowledge the uniqueness and individuality of the client, and facilitate the use of available resources accordingly (George, 2014). This understanding of the widow's needs can only be created by listening intently to the widow. According to Gudmundsdottir (2009), bereaved people need healthcare providers to witness and acknowledge their embodied experiences as they learn to live in a world without their significant other.

The important role that social networks play in the adjustment period after widowhood to process the loss (DiGiacomo et al., 2013; Wickert, 2010), is reflected in participants' requests for home visits and inclusion in peer support groups. Bereaved people 
have a need for connectedness with other people, to share feelings and memories and talk about what is still meaningful in their lives (Ribbens McCarthy, 2012). Maddrell (2016) touched on the need for research on bereavement support in different types of social spaces such as online support groups. Interventions should focus on assisting women to access affordable and reliable sources of support and to ensure meaningful interaction with peers and community (DiGiacomo et al., 2013).

Study participants' need for health information may improve their ability for self-care. Bereavement support focussing on self-care and health promotion in addition to emotional support may prevent prolonged and intense clinical distress (Utz et al., 2011). Importantly, primary healthcare nurses should avoid providing healthcare education based on stage theory of grief and grieving, as these theories fail to represent the complex emotions and processes associated with grieving. They lack empirical evidence and there are alternative models that better represent grieving processes (Stroebe, Schut, \& Boerner, 2017). Alternative models include a constructivist approach where a process of meaning-making is facilitated and the bereaved person encouraged to re-construct the connection with the deceased opposed to disengaging from the relationship (Silverman, 2004).

The study had some limitations. The sample size was small and included widows from three South African culture groups, therefore the results cannot be generalised to different culture groups and broader populations.

\section{Conclusion}

Our results clearly show that widows in South Africa have a need for support from primary healthcare nurses. Widows have a need to be treated in a person-centred way which means that their difficulties need to be acknowledged and they want to be regarded as individuals. Primary healthcare nurses need to spend time listening to widows in order to identify and 
manage their physical and psychological health concerns. By being empathetic, primary healthcare nurses might be able to identify widows at risk for complicated grief and refer them for appropriate treatment (Shear, 2012).

Peer support groups seem to play an important role in widows' recovery, and if not able to establish such groups, primary healthcare nurses might put together a database and refer widows to existing support groups in the community. Primary healthcare nurses should be able to provide healthcare information to widows, but should make sure that they are wellinformed in order to provide empirically based information (Stroebe et al., 2017).

\section{Declaration of Conflicting Interests}

The authors declared no potential conflicts of interest with respect to the research, authorship, and/or publication of this article.

\section{Acknowledgments}

The authors wish to acknowledge the contributions of the widows who participated in the study

\section{References}

Ali, A. A. \& Shanif, A. (2016). Stress, widowhood and psychological well-being: A case study. i-Manager's Journal on Nursing, 6(4), 35-39.

Asai, M., Fujimori, M., Akizuki, N., Inagaki, M., Matsui, Y., \& Uchitomi, Y. (2010). Psychological states and coping strategies after bereavement among the spouses of cancer patients: A qualitative study. Psycho-oncology, 19(1), 38-45. doi: 10.1002/pon.1444

Bennett, K. M., Gibbons, K., \& Mackenzie-Smith, P. T. (2010). Loss and restoration in later life: An examination of dual process model of coping with bereavement. OMEGA, 61(4), $315-332$.

Bennett, K. M., \& Soulsby, L. K. (2012). Wellbeing in bereavement and widowhood. Illness, Crisis \& Loss, 20(4), 321-337. 
Burns, N., \& Grove, S. K. (2011). Understanding nursing research: Building an evidencebased practice (5th ed.). Maryland Heights, MO: Elsevier Saunders.

Burns, R. A., C. J. Browning, C. J., \& Kendig, H. L. (2015). Examining the 16-year trajectories of mental health and wellbeing through the transition into widowhood. International Psychogeriatrics, 1 of 8. doi: https://doi.org/10.1017/S1041610215000472

Busari, A. O., \& Folaranmi, O. O. (2014). An empirical inquiry to psychological variables constituting stress: Middle aged widows in rural communities in Nigeria. Journal of Pan African Studies, 7(3), 210-222.

Carey, I. M., Shah, S. M., DeWilde, S., Harris, T., Victor, C. R., \& Cook, D. G. (2014). Increased risk of acute cardiovascular events after partner bereavement. A matched cohort study. JAMA Internal Medicine, 174(4), 598-605. doi:10.1001/jamainternmed.2013.14558

Carr, D., \& Bodnar-Deren, S. (2009). Gender, aging and widowhood. In P. Uhlenberg (Ed.), International Handbook of Population Aging, (pp. 705-728). Dordrecht: Springer.

Chatterjee, S. (2016). Widowhood - one of the darkest part of end of life span and its psychological turmoils. International Journal of Recent Scientific Research, 7(4), 1037410384.

Coleman, R. A., \& Neimeyer, R. A. (2010). Measuring meaning: Searching for and making sense of spousal loss in late-life. Death Studies, 34, 804-834.

Dahlberg, K., Dahlberg, H., \& Nyström, M. (2008). Reflective life world research (2nd ed.). Lund: Student literature.

Daoulah, A., Alama, M. N., Elkhateeb, O. E., Al-Murayeh, M., Al-Kaabi, S., Al-Faifi, S.M., Alosaimi, H. M.,...Alsheikh-Ali, A. A. (2017). Widowhood and severity of coronary artery disease: A multicenter study. Coronary Artery Disease, 28(2), 98-103.

Das, A. (2013). Spousal loss and health in late life: Moving beyond emotional trauma. Journal of Aging Health, 25(2): 221-242. doi:10.1177/0898264312464498

DiGiacomo, M., Davidson, P. M., Byles, J., \& Nolan, M. T. (2013). An integrative and socio - cultural perspective of health, wealth, and adjustment in widowhood. Health Care for Women in International, 34, 1067-1083.

Doherty, M. E., \& Scannell-Desch, E. (2008). The lived experience of widowhood during pregnancy. Journal of Midwifery \& Women's Health, 53(2), 103-109.

Garner, S. B. (1993). "Still Living Flesh": Beckett, Merleau-Ponty, and the Phenomenological body. Theatre Journal, 45(4), 443-460.

George J. B. (2014). Nursing Theories: The base for professional nursing practice (6th ed.). Harlow: Pearson Publishing. 
Giorgi, A. (2009). The descriptive phenomenological psychological method in Psychology: A modified Husserlian approach. Pennsylvania: Duquesne, University Press.

Gudmundsdottir, M. (2009). Embodied grief: Bereaved parents' narratives of their suffering body. OMEGA - Journal of Death and Dying, 59(3), 253-269.

Gupta, S., \& Bonanno, G. A. (2011). Complicated grief and deficits in emotional expressive flexibility. Journal of Abnormal Psychology, 120(3), 635-643.

Hamill, C., \& Sinclair, H. (2010). Bracketing - practical considerations in Husserlian phenomenological research. Nurse Researcher, 17(2), 16-24.

Kim, Y., \& Kim, C. (2016). Will the pain of losing a husband last forever? The effect of transition to widowhood on mental health. Development and Society, 45(1), 165-187 DOI $10.21588 / \mathrm{dns} / 2016.45 .1 .007$

Kwant, R. C. (1966). From Phenomenology to metaphysics: An inquiry into the last period of Merleau-Ponty's philosophical life. Pittsburgh and Louvain: Duquesne University Press.

Lee, G. R. (2014). Current research on widowhood: devastation and human resilience. Journals of Gerontology, Series B: Psychological Sciences and Social Sciences, 69(1), $2-$ 3, doi:10.1093/geronb/gbt111

Lobb, E. A., Rando, T. A., Doka, K. J., Fleming, S., Franco, M. H., Murray Parkes, C., \& Steele, R. (2012). A call to the field: Complicated grief in the DSM-5. Omega: Journal of Death \& Dying, 65(4), 251-255. http://doi.org/10.2190/OM.65.4.a

Lovey, C. (2016). A pilgrimage into the liminal: an experiential enquiry into the psychological and embodied space of grief and its representation in film. $\mathrm{PhD}$ thesis, University for the Creative Arts/University of Brighton.

Lowe, M., \& McClement, S. E. (2011). Spousal bereavement: The lived experience of young Canadian widows. Omega: Journal of Death \& Dying, 62(2), 127-148.

Lucci, L. A. (2011). The embodiment of grief in Blue note: A process - not the process (BA University of Calgary). Retrieved from http://nightswimmingtheatre.com/wp-content/ uploads/2011/09/Embodiment-of-Grief.pdf

Lund, D. A., Caserta, M., Utz, R., \& de Vries, B. (2010). Experiences and early coping of bereaved spouses/partners in an Intervention based on the Dual Process Model (DPM). Omega (Westport), 61(4), 291-313.

Maddrell, A. (2016). Mapping grief. A conceptual framework for understanding the spatial dimensions of bereavement, mourning and remembrance. Social \& Cultural Geography, 17(2), 166-188, DOI: 10.1080/14649365.2015.1075579 
McInnis, G. J., \& White, J. H. (2001). A phenomenological exploration of loneliness in the older adult. Archives of psychiatric nursing, 15(3), 128-139.

Merleau-Ponty, M. (1962). The phenomenology of perception (C. Smith, Trans.). London: Routledge \& Kegan Paul. (Original work published 1945.)

Merleau-Ponty, M. (1964). The visible and the invisible, trans, A. Lingis, Illinois: Northwestern University Press.

Merleau-Ponty, M. (1945/1962). Phenomenology of perception. London: Routledge \& Kegan.

Möller, J., Björkenstam, E., Ljung, R., \& Åberg Yngwe, M. (2011). Widowhood and the risk of psychiatric care, psychotropic medication and all-cause mortality: A cohort study of 658, 022 elderly people in Sweden. Aging \& Mental Health, 15(2), 259-266.

Muller, E. D., \& Thompson, C. L. (2003). The experience of grief after bereavement: A phenomenological study with implications for mental health counseling. Journal of Mental Health Counseling, 25(3), 183-203.

Perkins, J. M., Lee, H., James, K. S., Oh, J., Krishna, A., Heo, J., Lee, J., \& Subramanian, S.V. (2016). Marital status, widowhood duration, gender and health outcomes: A crosssectional study among older adults in India. BMC Public Health, 16:1032 DOI $10.1186 / \mathrm{s} 12889-016-3682-9$

Rodger, M. L., Sherwood, P., O'Connor, M., \& Leslie, G. (2007). Living beyond the unanticipated sudden death of a partner: A phenomenological study. OMEGA-Journal of Death and Dying, 54(2), 107-133.

Roelfs, D. J., Shorb, E., Currelic, M., Clemowd, L., Burge, M. M., \& Schwartzf, J. E. (2012). Widowhood and mortality: A meta-analysis and meta-regression. Demography, 49(2), 575-606. doi:10.1007/s13524-012-0096-X

Rogers, C. R. (1951/1961). On becoming a person: A therapist's view of psychotherapy. Western Behavioral Sciences Institute, La Jolla, California, Constable \& Company Ltd.

Rosnick, C. B., Small, B. J., \& Burton, A.M. (2010). The effect of spousal bereavement on cognitive functioning in a sample of older adults, aging, neuropsychology, and cognition. Psychology Press, 17, 257-269.

Ribbens McCarthy, J. (2012). Caring after death: Issues of embodiment and relationality. In C. Rogers, \& S. Weller (Eds), Critical approaches to care: Understanding caring relations, identities and cultures (pp. 183-194). London: Routledge. 
Ryckebosch-Dayez, A., Zech, E., Mac Cord J., \& Taverne, C. (2016). Daily life stressors and coping strategies during widowhood: A diary study after one year of bereavement. Death Studies, DOI: 10.1080/07481187.2016.1177750

Schut, H., \& Stroebe, M. (2010). Effects of support, counselling and therapy before and after the loss: Can we really help bereaved people? Psychologica Belgica, 50(1-2), 89-102.

Shear, M. K. (2012), Grief and mourning gone awry: Pathway and course of complicated grief. Dialogues in Clinical Neuroscience. 14, 119-128.

Silverman, P. R. (2004). Widow to widow: How the bereaved help one another (2nd ed.). New York: Brunner-Routledge.

Simon, N. M. (2013). Treating complicated grief. JAMA, 310(4), 416-423. doi:10.1001/jama.2013.8614

Stroebe, M., Schut, H., \& Stroebe, W. (2007). Health outcomes of bereavement, The Lancet, 370(9603), 1960-1973.

Stroebe, M., Schut, H., \& Boerner, K. (2017). Cautioning health-care professionals: Bereaved persons are misguided through the stages of grief. OMEGA-Journal of Death and Dying, $74(4), 455-473$.

Trivedi, J. K., Sareen, H., \& Dhyani, M. (2009). Psychological aspects of widowhood and divorce. Mens Sana Monographs, 7(1), 37-49. http://doi.org/10.4103/0973-1229.40648

Utz, R. L., Caserta, M., \& Lund, D. (2011). Grief, depressive symptoms, and physical health among recently bereaved spouses. The Gerontologist, 52(4), 460-471.

Van Wolputte, S. (2004). Hang on to your self: Of bodies, embodiment, and selves. Annual Review of Anthropology, 33, 251-269. doi: 10.1146/annurev.anthro.33.070203.143749

Vasunilashorn, S., \& Choi, K. (2014). Widowhood, age heterogamy, and health: The role of selection, marital quality, and health behaviors. Journals of Gerontology Series B: Psychological Sciences and Social Sciences, 69B(1), 123-134.

Wickert, J. L. (2010). Gender variations and coping with grief and loss issues in widowhood. (Unpublished master's thesis). California State University, Sacramento. 